\title{
Comparative Study Between Lemon Peel Extract and Testosterone Supplementation on the Hippocampus of Orchiectomized Rat
}

\author{
*Lubna Taher Mahmoud Eid., Mostafa Mahmoud El-Habeby., Neveen Mohamed El-Sherif., Manar Ali Faried \\ Department of Anatomy and Embryology, Faculty of Medicine, Menoufia University, Menoufia, Egypt.
}

Correspondence Author: Lubna Taher Mahmoud. Department of Anatomy and Embryology, Faculty of Medicine, Menoufia University, Menoufia, Egypt. E-mail: lubna.taher.90@gmail.com

Received date: 20 May 2019, Accepted date: 20 June 2019, Online date: 29 June 2019

Copyright: () 2019 Lubna Taher Mahmoud et al., This is an open-access article distributed under the terms of the Creative Commons Attribution License, which permits unrestricted use, distribution, and reproduction in any medium, provided the original author and source are credited.

\begin{abstract}
Background: The hippocampus is a sensitive region of the brain for testosterone action thus is vulnerable to post orchiectomy and age-related testosterone deficiency.

Objectives: The current work aimed to study the histological changes in the hippocampus of experimentally orchiectomized rats. Moreover, to the best of our knowledge, this research is the first attempt to assess the beneficial role of lemon peel extract supplementation in comparison with testosterone replacement.

Methods: Thirty adult male albino rats were divided into five groups; sham control, lemon peel treated $(200$ $\mathrm{mg} / \mathrm{kg} /$ day orally), orchiectomy (ORX), orchiectomy treated with lemon peel and orchiectomy treated with testosterone $(100 \mathrm{mg} / \mathrm{kg}$ i.m once). Thirty days later, the hippocampal sections were subjected to histological and immunohistochemical analyses for the expression of inducible nitric oxide (iNOS), Bax, glial fibrillary acidic protein (GFAP) and microtubule associated protein (Tau1). In addition, Total serum testosterone level was measured.

Results: Orchiectomy produced neurodegeneration with significant decrease of the pyramidal layer thickness, number of the pyramidal cells and their Nissl's granules content. Immunohistochemically, there was a significant upregulation of iNOS, a marker for oxidative stress, Bax, a proapoptotic marker, and GFAP, a marker for reactive astrocytes, with significant downregulation of Tau1, a microtubule associated protein, immunoreaction. In addition, serum total testosterone level was significantly decreased compared to the sham control group. Both testosterone and lemon peel treated groups ameliorated the orchiectomy induced hippocampal neurodegeneration via a significant downregulation of iNOS, Bax and GFAP expression and a significant upregulation of Tau1 expression. Moreover, the pyramidal layer thickness, the number of its pyramidal cells and their Nissl's granules content were significantly increased in both treated groups compared to the orchiectomized one. Furthermore, serum total testosterone level was significantly increased compared to the orchiectomized group.

Conclusion: testosterone depletion due to orchiectomy produced hippocampal neurodegenerative changes. Administration of testosterone or lemon peel extract improved these changes.
\end{abstract}

Keywords: lemon peel extract, hippocampus, orchiectomy, testosterone replacement

\section{INTRODUCTION}

Physiologically, androgens are involved in development, differentiation, and survival of neurons (Hammond et al., 2001). With aging, the testosterone level in men begins to decline (Feldman et al., 2002) leading to changes in androgen responsive tissues as the hippocampus, prostate, heart, and skin (Moore and Urban, 2004). Therefore, the hippocampus is a target for testosterone action and hence is vulnerable to gradual age-related decline of testosterone level in men (Elnegris and Mohamed, 2012).

The hippocampus plays a crucial role in the consolidation of memories (Jacobs et al., 2013); consequently, a brain lesion causing hippocampal damage results in anterograde amnesia (Gregory et al., 2014).

Orchiectomy is a way of studying the consequences of testosterone deficiency in animal models (Mohamed et al., 2014). Androgen depletion leads to apoptosis of neurons (Hammond et al., 2001) with the release of some proteins, including proapoptotic and antiapoptotic proteins. Moreover, testosterone deficiency leads to excess production of reactive oxygen species (ROS) and reduction of antioxidant agents responsible for the metabolism of ROS (Abdel Moneim, 2014). 
Tau, a microtubule-associated protein, promotes the stabilization of neuronal microtubules, which are essential in outgrowth and axonal transport) Spires-Jones et al., 2009). It is phosphorylated at specific sites during fetal life, becomes dephosphorylated around birth, and remains non-phosphorylated in a healthy life. In pathological conditions, these sites become abnormally phosphorylated. It has six different isoforms in the adult brain, including Tau-1 (Goedert et al., 1993).

Testosterone can reduce hippocampal neurodegeneration (Rhodes and Frye, 2004). However, it is contraindicated in some conditions and produces side effects on long term therapy (Osterberg et al., 2014). Therefore, studies are looking for a natural product which can elevate serum testosterone level with fewer hormonal side effects thus can be used as an alternative treatment or supplementation of hormonal therapy for hypogonadism.

Citrus peels are waste materials of citrus fruits obtained after extraction of their juice. They are an essential source of antioxidants, such as ascorbic acid and flavonoids, so they can reduce the oxidative damage (Jayaprakash and Patil, 2007) by neutralizing the oxidizing free radicals and inhibiting lipid peroxidation (Abdel Moneim, 2014). Also, citrus flavonoids have anticancer, anti-inflammatory, antidiabetic, and antiallergic activities (Ortuno et al., 2006). Moreover, citrus peels increase the serum testosterone level) Hong et al., 2008).

Consequently, the present study was designed to investigate, for the first time to the best of our knowledge, the effect of lemon peel extract compared to testosterone replacement on the post-orchiectomy hippocampal neurodegeneration.

\subsection{Animals:}

\section{MATERIALS AND METHODS}

Thirty adult male albino rats with average weight of 180-200 grams were used in this study. They were obtained from Theodor Bilharz Research Institute Animal House, Cairo, Egypt. The animals were kept under controlled conditions of temperature and humidity and provided with water and balanced diet. The light $\backslash$ darkness cycle was fixed at 12:12 h. The procedure was approved by the ethics committee on animal experiment of the Faculty of Medicine, Menoufia University, Egypt in accordance with the international regulations on care and use of laboratory animals.

The rats were divided into five groups, each group consisted of six rats: Group I (sham control group): The rats were subjected to sham surgical procedure and left without treatment. Group II (lemon peel treated group): The rats were subjected to sham surgical procedure then received lemon peel extract in a dose of (200 mg/kg/day) (Mohamed et al., 2014) dissolved in $2 \mathrm{ml}$ of distilled water per oral once daily using gastric tube. Group III (orchiectomy group): The rats were subjected to orchiectomy and left without treatment. Group IV (Orchiectomized rats treated with lemon peel extract): The rats were subjected to orchiectomy then received the same dose of lemon peel extract. Group V (Orchiectomized rats treated with testosterone): They were subjected to orchiectomy then received a single intramuscular injection of testosterone undecanoate (100mg/kg) (Rhoden et al., 2017). The experimental duration was 30 days.

\subsection{Chemicals:}

Testosterone undecanoate (Nebido, $1000 \mathrm{mg} / 4 \mathrm{ml}$ solution) is a product of Bayer Pharma AG obtained from El-Ezaby pharmacy, Cairo, Egypt in the form of vials.

Lemon fruits were collected from the local market, Egypt in August and September. The plant material was authenticated in Botany Department, National Research Center, El-Doki, Cairo, Egypt. Fresh fruit peels of lemon were taken and dried for 10 days then macerated in ethanol for one day. The ethanol was removed under reduced pressure to obtain a semisolid mass of ethanolic extract. The ethanolic extract was then stored in $-20^{\circ} \mathrm{C}$ until used (Mohamed et al., 2014).

\subsection{Surgical procedure:}

The rats were anesthetized with ketamine (intraperitoneal injection of a single dose of $50 \mathrm{mg} / \mathrm{kg}$ body weight) (Ozcan et al., 2015). A small vertical midline scrotal incision was made, and the testes were exposed through it. In the sham-operated group, the testes were exposed, manipulated, and then replaced into the scrotum. In the orchiectomy group, the testes were bilaterally removed after ligature of the spermatic cord; then the incision was sutured (Ogawa et al., 1999). Garamycin cream was applied locally as a wound dressing for 5 days post-operative to reduce the risk of wound infection (El-Mehi and El-Sherif, 2014). 
Citation: Lubna Taher Mahmoud Eid, et al., Comparative Study Between Lemon Peel Extract and Testosterone Supplementation on the Hippocampus of Orchiectomized Rat. Australian Journal of Basic and Applied Sciences, 13(6): 62-73. DOI: 10.22587/ajbas.2019.13.6.7
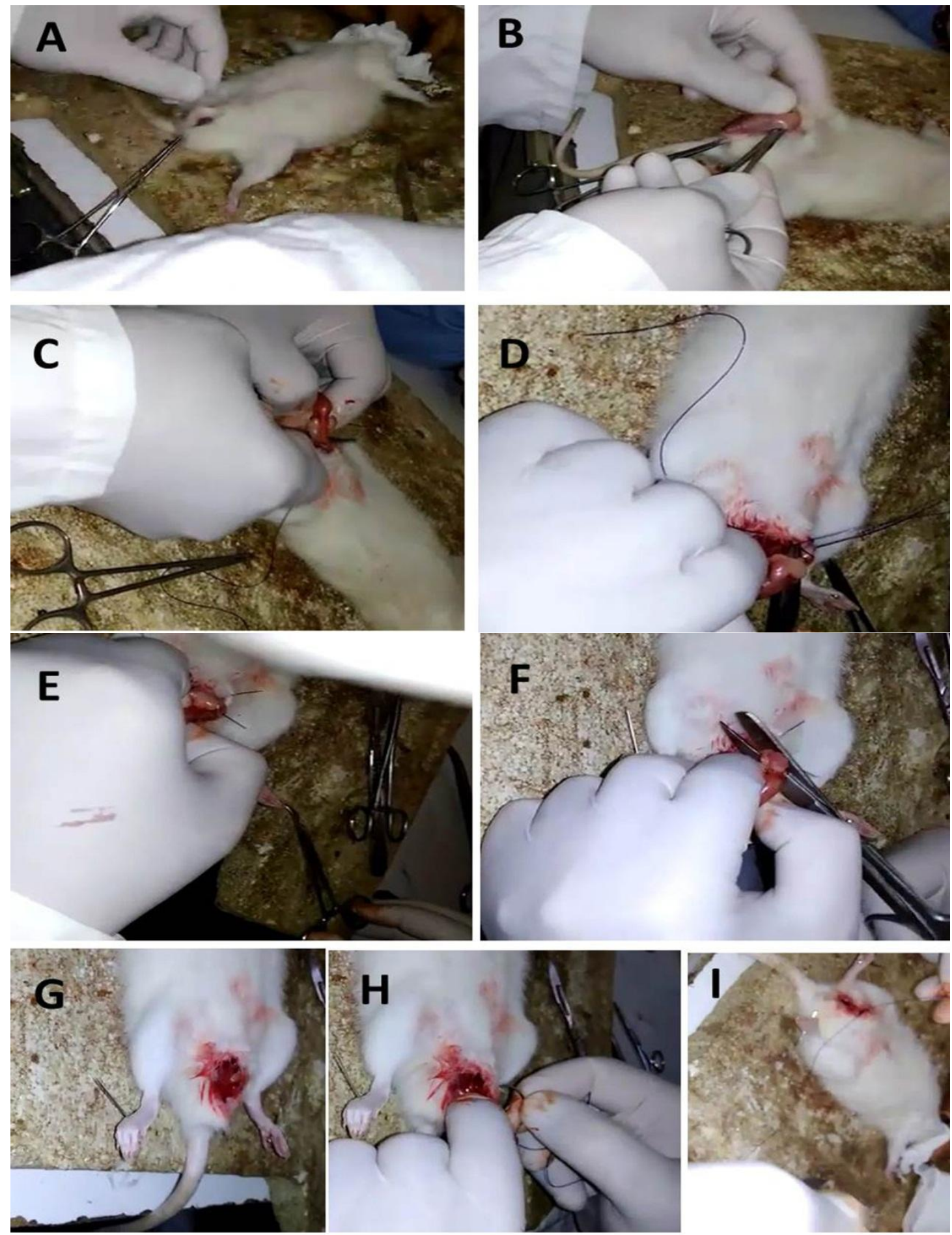

Figure 1: A photograph showing steps of orchiectomy. A: vertical incision of the scrotum. B: extraction of its contents. C, D, E ligature of the spermatic cord. F, G: removal of testis. H, I: closure of the scrotum.

At the end of the experiment, rats were anesthetized using diethyl ether inhalation; blood samples were collected from the retro-orbital venous plexus for biochemical analysis and craniotomy was performed to dissect out the intact brains to examine the hippocampus.

\subsection{Evaluation methods:}

\subsubsection{Biochemical study:}

The collected blood samples were centrifuged at $3000 \mathrm{~g}$ for $10 \mathrm{~min}$. Serum concentrations of testosterone were quantified using commercial immunoassays. To avoid the difference in testosterone level, all blood samples were taken at a fixed time in the mornings (Stuermer et al., 2009).

2.4.2. Histological study:

The cerebral hemisphere was cut coronally into two halves to reach the site of the hippocampus and then fixed in $10 \%$ buffered formaldehyde solution then the specimens were dehydrated, cleared, and embedded in paraffin blocks. Serial coronal sections 
Citation: Lubna Taher Mahmoud Eid, et al., Comparative Study Between Lemon Peel Extract and Testosterone Supplementation on the Hippocampus of Orchiectomized Rat. Australian Journal of Basic and Applied Sciences, 13(6): 62-73. DOI: 10.22587/ajbas.2019.13.6.7

were cut $5 \mu \mathrm{m}$ thick and stained with hematoxylin and eosin ( $\mathrm{H} \& \mathrm{E}$ ) for routine histological examination and with toluidine blue (TB) to detect Nissl's granules.

2.4.3. Immunohistochemical study:

The paraffin sections on poly-L-lysin coated slides were deparaffinized and rehydrated. Endogenous peroxidase was blocked by inserting the sections in $3 \%$ hydrogen peroxide $\left(\mathrm{H}_{2} \mathrm{O}_{2}\right)$. The microwave antigen retrieval procedure was performed. The sections were incubated with primary anti iNOS antibody, a marker for oxidative stress- cytoplasmic expression, (rabbit polyclonal antibody, Midco Trade Company, Giza, Egypt); anti Bax antibody, a proapoptotic marker- cytoplasmic expression, (rabbit polyclonal antibody, Dako, Carpinteria California, USA); anti GFAP antibody, a marker for astrocyte activation, (rabbit polyclonal antibody, Midco Trade Company, Giza, Egypt) and anti Tau-1 antibody, expressed in the axons and cytoplasm of pyramidal cells, (mouse monoclonal antibody, Gene tex company, Cairo, Egypt). After that, biotinylated goat-polyvalent secondary antibody was applied. The sections were then incubated in preformed streptavidin-peroxidase and finally the prepared DAB substrate chromogen (3,3'-diaminobenzidine tetrahydrochloride) was applied and the slides were counterstained with hematoxylin to be examined under light microscope.

\subsection{Morphometric assessment:}

For histological and immunohistochemical quantitative assessment, from each section five non-overlapping fields (400x) were randomly captured by a Leica Microscope DML B2/11888111 equipped with a Leica camera DFC450. The different parameters including the thickness of the pyramidal layer, number of pyramidal cells, the color intensity of toluidine blue, number of GFAP positive cells, percentage of Bax positive pyramidal cells, percentage of iNOS positive pyramidal cells and the area percentage of tau-1 immunoreaction were assessed in the fields taken from at least five sections / animal using image $\mathbf{J}$ software (Maryland, USA) and averaged per field for each animal. The calculated data for at least five animals / experimental group and the biochemical results were statistically analyzed.

\subsection{Statistical analysis:}

The collected data were presented as mean \pm SD. Data analysis was performed using SPSS (Inc., Chicago, IL, USA) version 23 on IBM compatible computer. The obtained data were analyzed using one way-ANOVA followed by post hoc Bonferroni test. The results were considered statistically significant and nonsignificant when the p-values were $<0.05$ and $>0.05$ respectively.

\section{Results}

There was a non-significant difference in all the examined parameters between the sham control and sham control treated with lemon peel extract. Therefore, they were pooled in one control group.

\subsection{Biochemical results}

Total serum testosterone level in the orchiectomy group showed a highly significant decrease $(\mathrm{P}<0.001)$ compared with the sham control group $(0.85 \pm 0.16$ vs. $4.75 \pm 0.24)$. In the orchiectomy group either that treated with lemon peel extract or that treated with testosterone, this hormone was significantly increased $(\mathrm{P}<0.001)$ as compared with the orchiectomy group $(2.15 \pm 0.19$ and $4.26 \pm 0.21$ respectively vs. $0.85 \pm 0.16)$. However, a significant increase $(\mathrm{P}<0.001)$ was observed in the orchiectomy group treated with testosterone as compared with that treated with lemon (4.26 \pm 0.21 vs $2.15 \pm 0.19)$ (Figure 2).

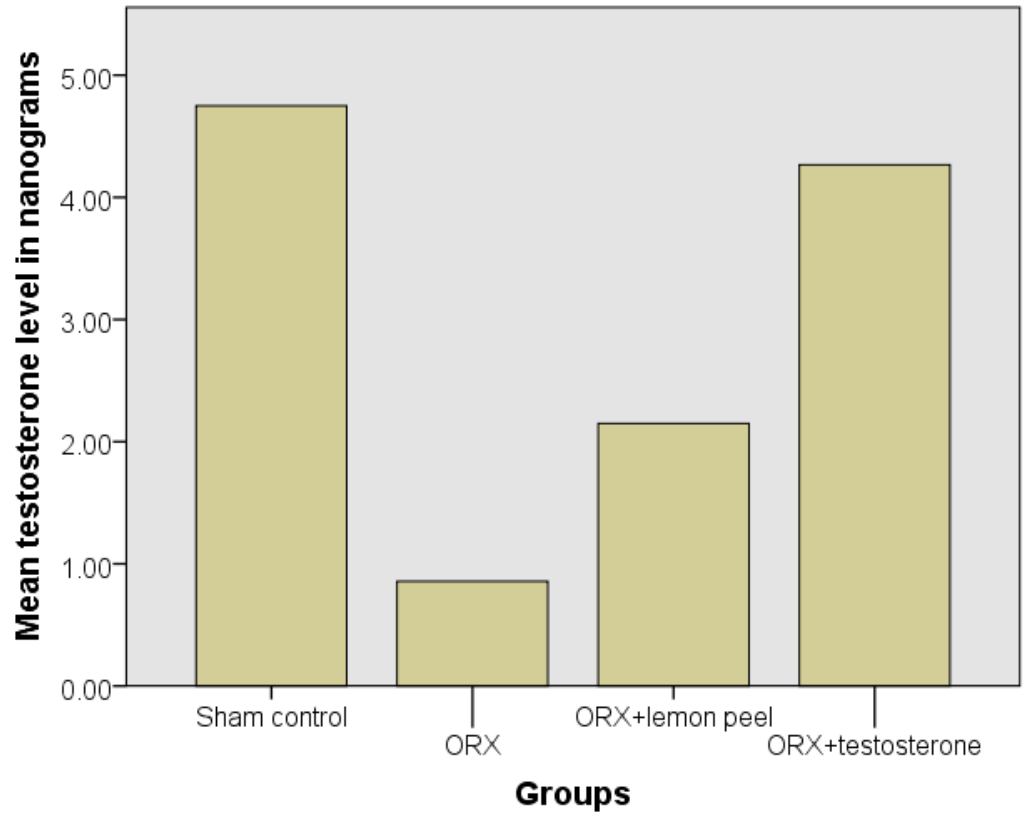

\subsection{Histological results}

Figure 2: Total testosterone hormone levels

In H\&E-stained sections, CA1 region of the hippocampus of the sham control group was formed of molecular, pyramidal and polymorphic layers. The pyramidal layer was formed of multiple regular rows of well-organized compactly arranged pyramidal cells. Each pyramidal cell appeared triangular with basophilic cytoplasm, large vesicular nucleus, and prominent nucleolus. Both molecular and polymorphic layers were formed mainly of eosinophilic neuropil matrix within which neuroglia was embedded. Microglia with rod-shaped nuclei, oligodendroglia with small dark nuclei and perinuclear halos and astrocytes with oval vesicular nuclei were observed (Figure 3A). In the orchiectomy group, there was a disturbing arrangement of the pyramidal cells that 
Citation: Lubna Taher Mahmoud Eid, et al., Comparative Study Between Lemon Peel Extract and Testosterone Supplementation on the Hippocampus of Orchiectomized Rat. Australian Journal of Basic and Applied Sciences, 13(6): 62-73. DOI: 10.22587/ajbas.2019.13.6.7

appeared degenerated with shrunken hyperchromatic nuclei, perinuclear halos, and lost nuclear details. The neuropil showed many vacuolations and congested blood vessels. Moreover, the number of astrocytes was increased compared with the sham control group (Figure 3B). In the orchiectomized group treated with lemon peel extract, many normal pyramidal cells were observed with only some pyknotic ones and few ghost cells. The neuropil was regularly organized except for the presence of few vacuolations and mildly congested blood vessels. Moreover, few astrocytes were observed (Figure 3C). In the orchiectomized group treated with testosterone, the pyramidal cell layer appeared almost normal, well organized with normal pyramidal cells; however, few degenerated ones and few astrocytes were observed (Figure 3D).

Statistically: The thickness of the pyramidal layer was significantly decreased $(\mathrm{P}<0.001)$ in the orchiectomized group compared with the sham control one $(20.27 \pm 4.77$ vs. $49.85 \pm 2.86)$. However, it showed a significant increase $(\mathrm{P}<0.001)$ in both lemon and testosterone-treated groups compared with the orchiectomy group $(42.07 \pm 1.88$ and $45.44 \pm 0.72$, respectively vs. 20.27 44.77). Also, there was a non- significant difference $(\mathrm{P}>0.05)$ in the testosterone-treated the group as compared with the lemon treated one (45.44 \pm 0.72 vs. $42.07 \pm 1.88)$ (Figure 4$)$.

Moreover, the number of the pyramidal cells was significantly decreased $(\mathrm{P}<0.001)$ in the orchiectomized group compared with the sham control one $(34.83 \pm 4.16$ vs. $76.66 \pm 3.20)$. However, it showed a significant increase $(\mathrm{P}<0.001)$ in both lemon and

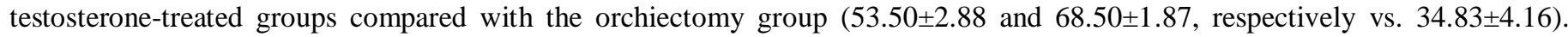
Also, there was a significant increase $(\mathrm{P}<0.001)$ in the testosterone-treated the group as compared with the lemon treated one $(68.50 \pm 1.87$ vs. $53.50 \pm 2.88)$ (Figure 4$)$.
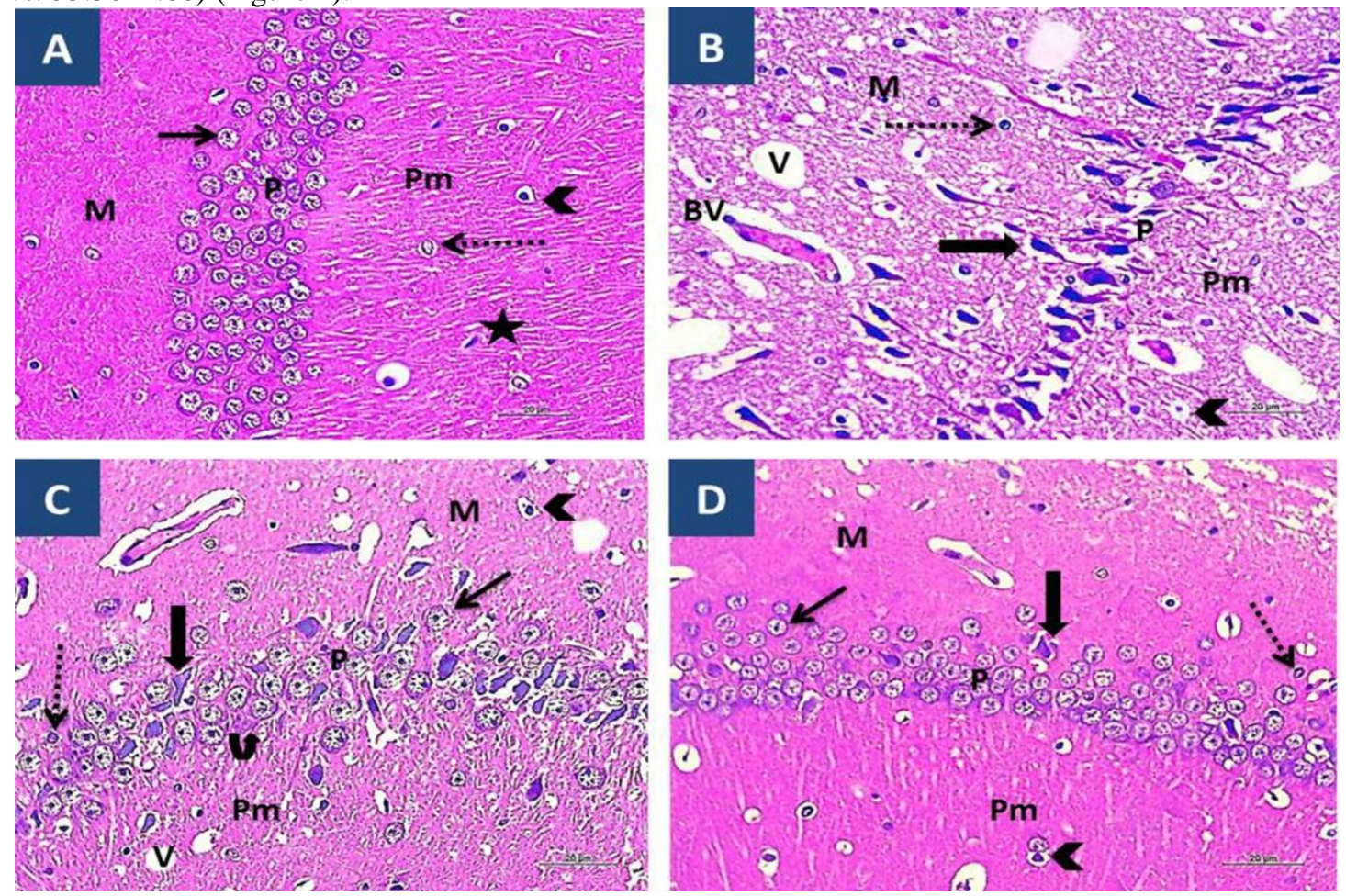

Figure 3: Representative photomicrographs of coronal sections at the CA1 area of the hippocampus of the different groups showing the pyramidal (P), molecular (M) and polymorphic (Pm) layers. (A) The sham control group showing normal pyramidal cells (thin arrow). Microglia (star), oligodendroglia (arrowhead) and astrocyte (dashed arrow) are scattered inside the neuropil. (B) The orchiectomy group showing pyknotic pyramidal cells (thick arrow), vacuolations (V), congested blood vessels (BV), degenerated oligodendroglia (arrow head) and numerous astrocytes (dashed arrow). (C) Orchiectomy group treated with lemon peel extract showing many normal pyramidal cells (thin arrow) but some pyknotic (thick arrow) and ghost cells (curved arrow) are still present. Normal oligodendroglia (arrow head), few astrocytes (dashed arrow) and few vacuolations (V) are observed within the neuropil. (D) Orchiectomy group treated with testosterone showing normal pyramidal cells (thin arrow) with few degenerated ones (thick arrow). The neuropil shows few astrocytes (dashed arrow) and normal oligodendroglia (arrow head) (scale bar 20 $\mathrm{X} 400)$. 
Citation: Lubna Taher Mahmoud Eid, et al., Comparative Study Between Lemon Peel Extract and Testosterone Supplementation on the Hippocampus of Orchiectomized Rat. Australian Journal of Basic and Applied Sciences, 13(6): 62-73. DOI: 10.22587/ajbas.2019.13.6.7
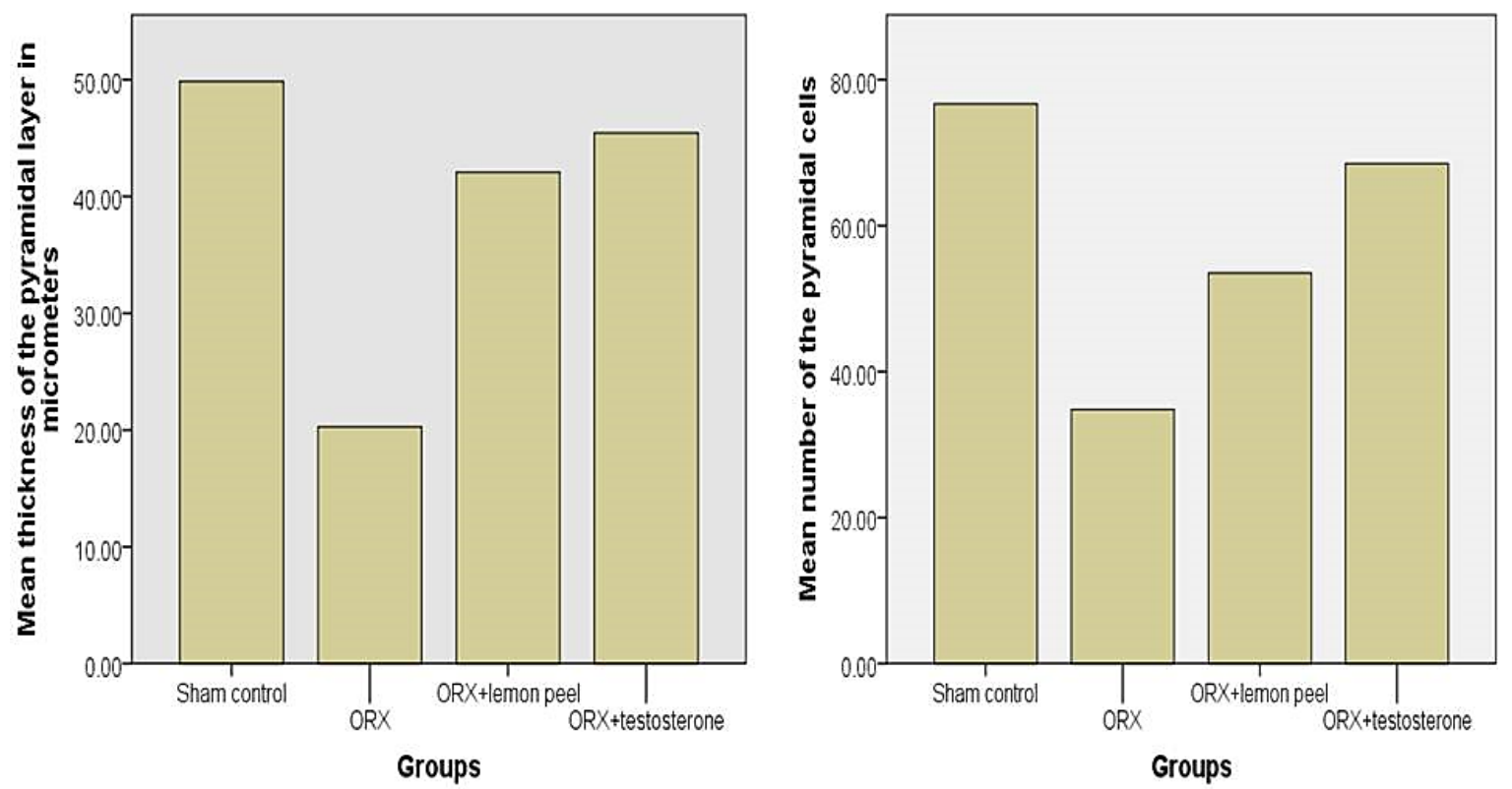

Figure 4: Mean thickness of the pyramidal layer in micrometers and the mean number of the pyramidal cells

In TB-stained sections, the cytoplasm of the pyramidal cells of the sham control group was filled with dense dark blue Nissl's granules. In the orchiectomy group, the Nissl's granules content appeared faint blue in color. In both testosterone and lemon treated groups, the Nissl's granules content appeared dark blue (Figure 5). Statistically: a significant decrease $(\mathrm{P}<0.001)$ in the color intensity was observed in the orchiectomy group as compared with the sham control group (74.66 \pm 1.69 vs. 130.73 \pm 5.79 ). However, there was a significant increase $(\mathrm{P}<0.001)$ in both lemon peel and testosterone treated groups as compared with the orchiectomy group $(106.73 \pm 4.13$ and $122.57 \pm 2.54$, respectively vs. $74.66 \pm 1.69)$. Also, there was a significant increase $(\mathrm{P}<0.001)$ in the orchiectomy group treated with testosterone as compared with that treated with lemon peel extract $(122.57 \pm 2.54 \mathrm{vs}$.

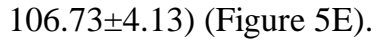
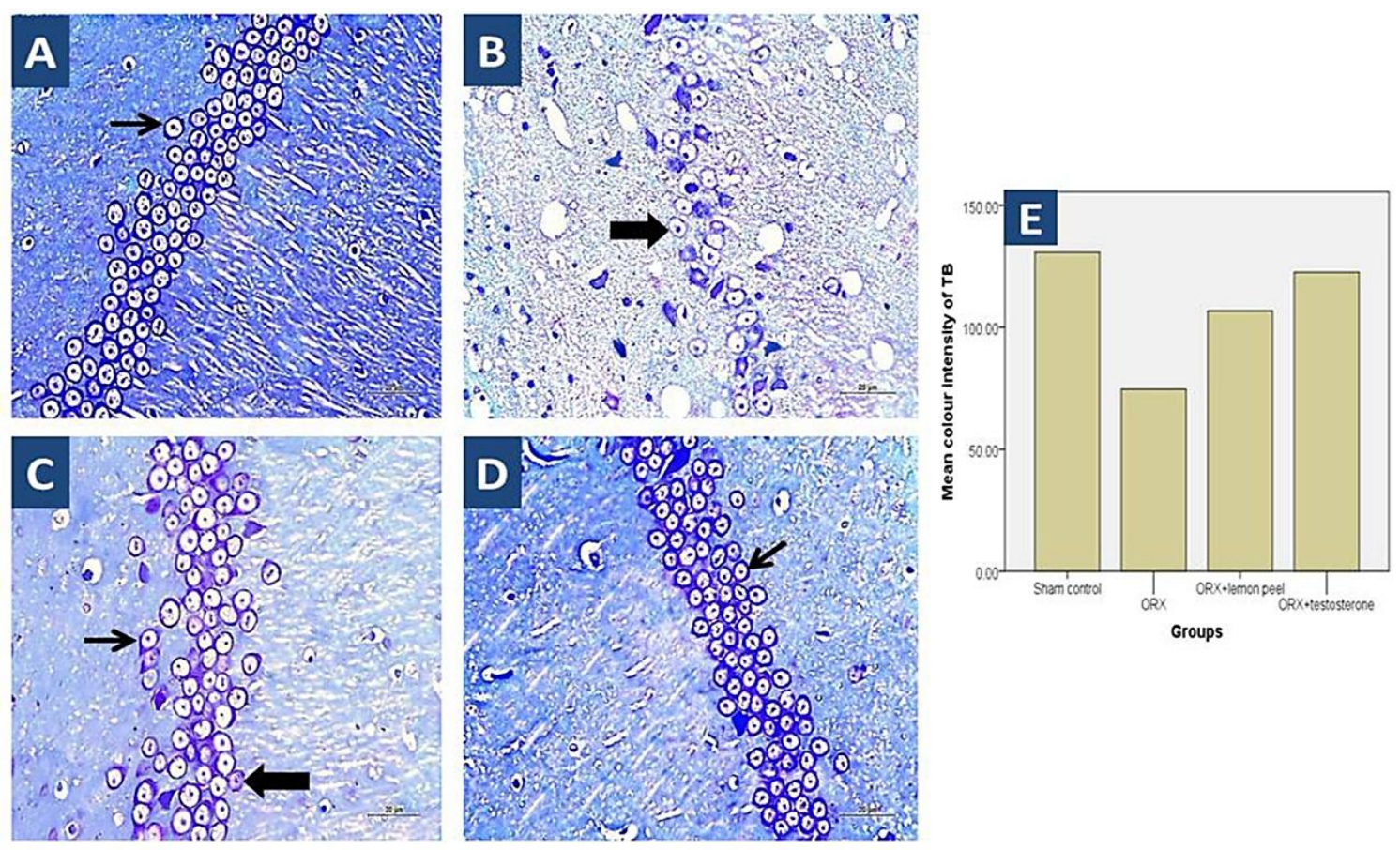

Figure 5: Photomicrographs of TB-stained sections in the CA1 region of the hippocampus proper. (A) Sham control group showing dense dark blue Nissl's granules content inside the cytoplasm of the pyramidal cells (thin arrows). (B) Orchiectomy group showing an apparent decrease of Nissl's granules content inside the cytoplasm of the pyramidal cells that appeared faint blue (thick arrows). (C) Orchiectomy group treated with lemon peel extract showing increased Nissl's granules content in many of the pyramidal cells which appeared dark blue (thin arrow) with only a few faint blue Nissl's granules (thick arrow). (D) Orchiectomy group treated with testosterone showing an apparent increase in Nissl's granules content in the pyramidal cells that appeared dark blue in color (thin arrows) (scale bar 20 X400). (E) Mean color intensity of Nissl's granules. 
Citation: Lubna Taher Mahmoud Eid, et al., Comparative Study Between Lemon Peel Extract and Testosterone Supplementation on the Hippocampus of Orchiectomized Rat. Australian Journal of Basic and Applied Sciences, 13(6): 62-73. DOI: 10.22587/ajbas.2019.13.6.7

\subsection{Immunohistochemical results}

In iNOS stained sections, the orchiectomy group showed a significant increase $(\mathrm{P}<0.001)$ in the percentage of iNOS positive cells compared to the sham control group (89.30 \pm 8.58 vs. 1.46 \pm 0.86$)$. However, in orchiectomy groups either treated with lemon peel extract or testosterone, a significant decrease $(\mathrm{P}<0.001)$ in this percentage was observed compared to the orchiectomy group $(26.33 \pm 2.52$ and $14.32 \pm 3.04$ respectively vs. 89.30). Also, the percentage was significantly decreased $(\mathrm{P}<0.001)$ in the orchiectomy group treated with testosterone when compared with that treated with lemon peel extract (14.32 \pm 3.04 vs. 26.33 \pm 2.52$)$ (Figures 6 a-d, 7A).

In Bax stained sections, the orchiectomy group showed a significant increase $(\mathrm{P}<0.001)$ in the percentage of Bax positive cells

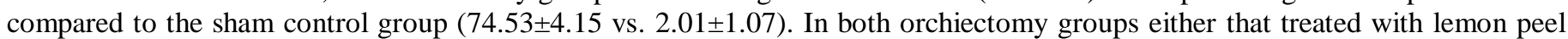
extract or testosterone, a significant decrease $(\mathrm{P}<0.001)$ in this percentage was observed compared to the orchiectomy group $(17.75 \pm 2.17$ and $8.45 \pm 1.57$ respectively vs. $74.53 \pm 4.15)$. However, the percentage was significantly decreased $(\mathrm{P}<0.001)$ in the orchiectomy group treated with testosterone when compared with that treated with lemon peel extract $(8.45 \pm 1.57 \mathrm{vs}$. 17.75 \pm 2.17$)$ (Figures 6 e-h, 7B).

In GFAP stained sections, the orchiectomy group showed a significant increase $(\mathrm{p}<0.001)$ in the number of astrocytes

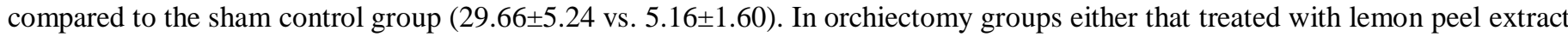
or testosterone, there was a significant decrease $(\mathrm{p}<0.001)$ in the number of astrocytes compared to the orchiectomy group $(14.16 \pm 1.94$ and $8.33 \pm 1.36$ respectively vs. 29.66). However, there was a significant decrease $(\mathrm{P}<0.05)$ in their number in the orchiectomy group treated with testosterone as compared with that treated with lemon peel extract $(8.33 \pm 1.36$ vs. 14.16 \pm 1.94$)$ (Figures 6i-1, 7C).

In Tau-1 stained sections, the orchiectomy group showed a significant decrease $(\mathrm{P}<0.001)$ in its area percentage compared to the sham control group $(27.04 \pm 5.80$ vs. $83.97 \pm 1.95)$. Both orchiectomy groups either treated with lemon peel extract or testosterone showed a significant increase $(\mathrm{P}<0.001)$ in area percentage of Tau-1 compared to the orchiectomy group $(64.31 \pm 3.62$ and 78.03 \pm 1.13 respectively vs. 27.04 \pm 5.80 ). However, the percentage of the orchiectomy group treated with testosterone was significantly increased $(\mathrm{P}<0.001)$ compared to that treated with lemon peel extract $(78.31 \pm 1.31$ vs. 64.31 \pm 3.62$)$ (Figures $6 \mathrm{~m}-$ $\mathrm{p}, 7 \mathrm{D})$.
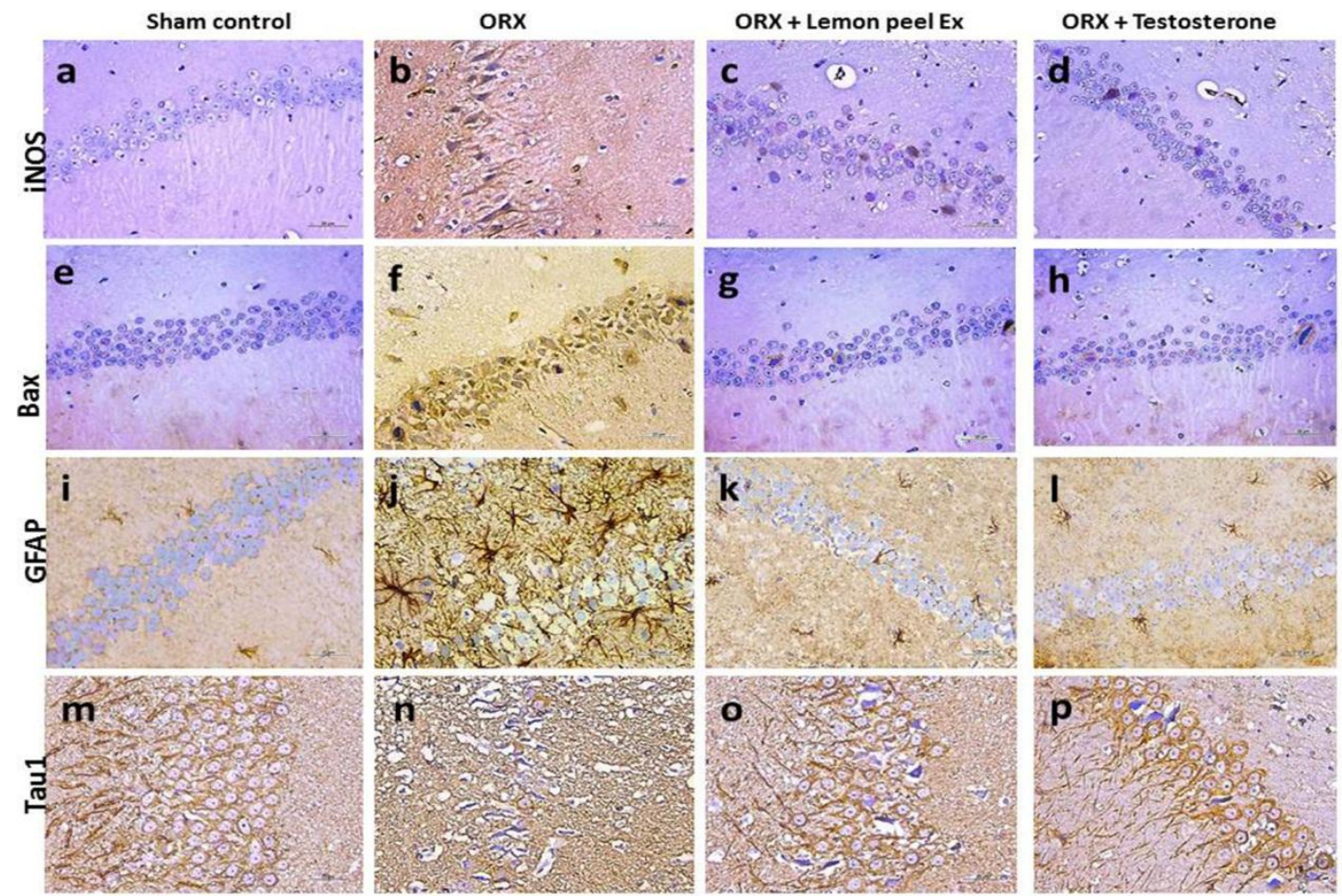

Figure 6: Representative micrographs of the different experimental groups showing a significant upregulation of the iNOS (a-d), Bax (e-h) and GFAP (i-l) immunoreaction in the orchiectomy group and their downregulation in both lemon peel extract and testosterone-treated groups. Tau1 stained sections (m-p) showing a significant downregulation in the orchiectomy group and upregulation in both lemon peel extract and testosterone-treated groups (scale bar 20 X400). 
Citation: Lubna Taher Mahmoud Eid, et al., Comparative Study Between Lemon Peel Extract and Testosterone Supplementation on the Hippocampus of Orchiectomized Rat. Australian Journal of Basic and Applied Sciences, 13(6): 62-73. DOI: 10.22587/ajbas.2019.13.6.7
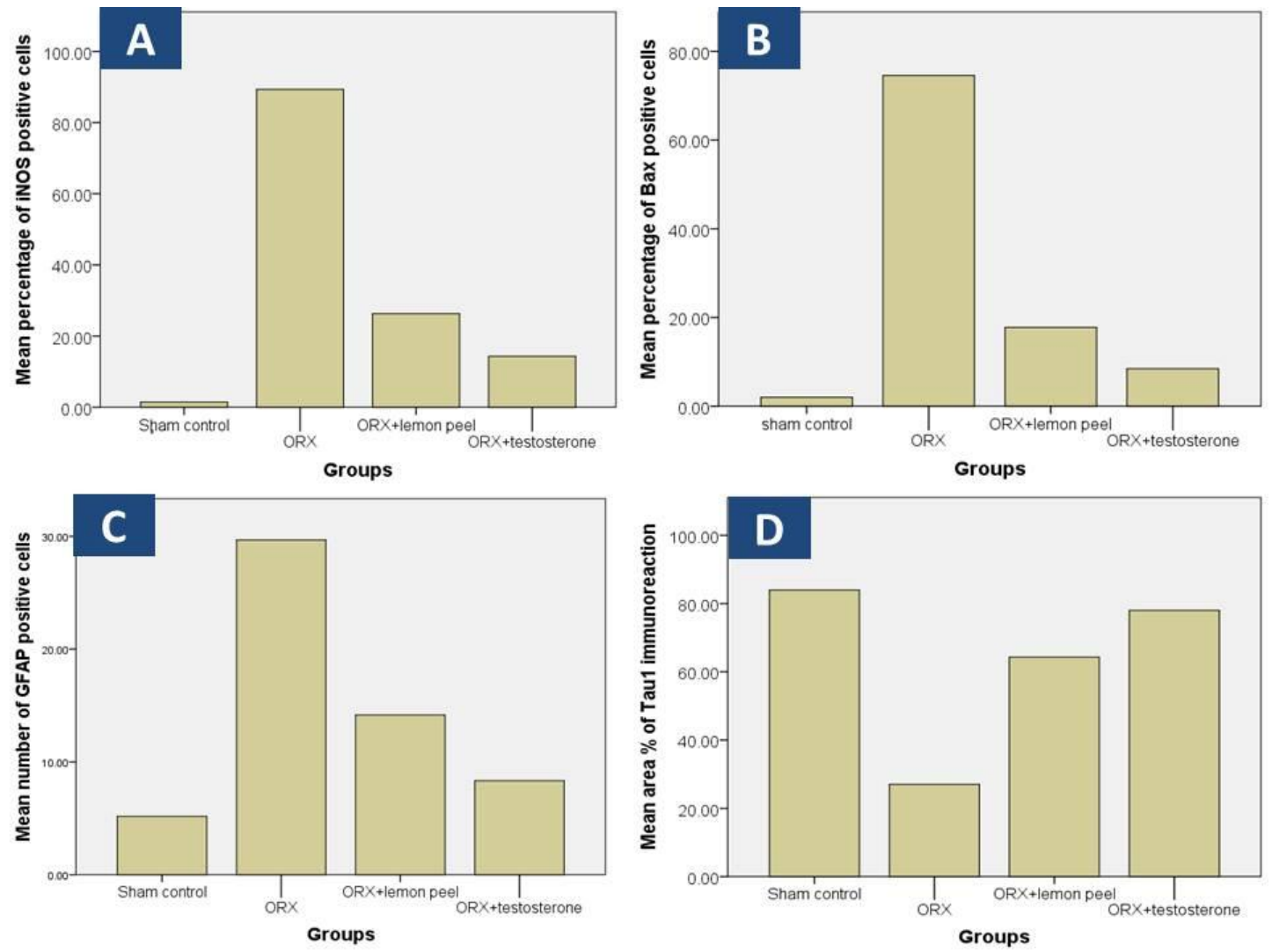

Figure 7: (A) Mean percentage of iNOS positive cells. (B) Mean percentage of Bax positive cells. (C) Mean number of astrocytes. (D) Mean area percentage of Tau-1 immunoreaction.

\section{DISCUSSION}

Testosterone is considered a neurosteroid (Barreto et al., 2007) that plays an important role in neuroprotection (Bancroft, 2005). It acts through intracellular androgen receptors (ARs), which are abundant in the hippocampus (Stuermer et al., 2009). With aging, testosterone level declines gradually leading to neurodegenerative changes in the hippocampus) Feldman et al., 2002).

Orchiectomy is considered the standard gold treatment for testicular cancer) Kordan, 2010), some cases with prostatic cancer) Demir et al., 2015) and testicular torsion (Berman et al., 2012). Experimental model for orchiectomy was used to study consequences of testosterone deficiency, which occurs with aging, post orchiectomy or due to disorders interrupting the secretion of testosterone (Ryu et al., 2015).

In the present work, bilateral scrotal approach orchiectomy was performed to maintain a lower level of testosterone and to enhance the healing. This was in line with previous studies conducted by Christoffersen et al., 2006; Carla et al., 2012; Shin et al., 2016.

Testosterone is used as hormone replacement for hypogonadism) Traish et al., 2009). However, it is contraindicated in several conditions, including benign prostatic hyperplasia, prostate cancer, breast cancer, and congestive heart failure. Also, its long-term therapy has many side effects) Osterberg et al., 2014). Therefore, this study aimed to look for a natural product which can elevate the serum testosterone level with avoiding the hormonal side effects thus can be used as an alternative treatment or supplementation of hormonal therapy for hypogonadism.

In the present study, the hippocampus of the orchiectomized rats revealed a significant decrease in the thickness of the pyramidal cell layer and the number of its cells. Moreover, the hippocampal tissue showed many degenerative changes in the form of degenerated pyknotic pyramidal cells, mostly apoptotic which was supported by a significant upregulation of Bax, with a significant decrease of their Nissl's granules content. Some cells were swollen, and others were ghost-like cells. The neuropil of the molecular and polymorphic layers showed many congested blood vessels, vacuolations and increase in the number of astrocytes which was confirmed by the significant increase in the number of GFAP immunoreactive astrocytes.

Similar findings were conducted by Mohamed and Elnegris (2012). This may be attributed to the significant decrease in testosterone level as supported by Medyan et al. (2010) who clarified that decreased serum testosterone level resulted in impaired hippocampal neurogenesis and increased oxidative stress-inducing neuronal cell death. This was confirmed in our study by the significant upregulation of iNOS, a marker for oxidative stress, that led to the activation of Bax pathway that may be responsible for the considerable decrease in the thickness of the pyramidal cell layer and the number of its cells. This was in agreement with DeKosky and Scheff (1990) who referred the decrease in the pyramidal cell layer thickness to the reduction in neuronal and synapse number. Salcedo et al. (2012) explained the reduction in hippocampal thickness by the free radical theory of aging which suggested that an elevation in reactive oxygen species (ROS) damages neural membranes and induces oxidative stress. 
Citation: Lubna Taher Mahmoud Eid, et al., Comparative Study Between Lemon Peel Extract and Testosterone Supplementation on the Hippocampus of Orchiectomized Rat. Australian Journal of Basic and Applied Sciences, 13(6): 62-73. DOI: 10.22587/ajbas.2019.13.6.7

Reali et al. (2005) and Bagetta et al. (2004) stated that iNOS-derived NO is a mediator of neurotoxicity as it might execute apoptotic death in neurons by activation of the apoptotic cascade. To initiate apoptosis, NO can induce mitochondrial dysfunction (Marriott et al., 2004) and upregulate proapoptotic factors (Tamatani et al., 1998). Additionally, it can directly react with superoxide to produce peroxynitrite (Johnson et al., 2001) which serves as a strong oxidizing agent that reacts with all classes of biomolecules causing oxidative stress-inducing damage of deoxy ribonucleic acid (DNA), proteins and lipids (Acquaviva et al., 2004).

This explanation was in agreement with Afolabi et al. (2013) and Khasnavis et al. (2017) who stated that castration resulted in a dramatic increase in ROS and significant reduction of critical ROS-detoxifying enzymes. Furthermore, Klapcinska et al. (2008) reported that the antioxidant defense system was negatively affected after gonadectomy through a decrease in the antioxidant enzyme levels.

A significant increase in GFAP immunoreactive cells in the hippocampus of the orchiectomized rats was in line with Garcia and Melcangi (2006). This may be attributed to the oxidative stress induced reactive gliosis. Also, Cencioni et al. (2013) added that astrocytosis was detected in aging and other damaging conditions like stress and ischemia. Ramesh et al. (2013) stated that astrocytes represent the most abundant glial cell type in the central nervous system (CNS) and that once these cells undergo reactive activation, they produce cytokines and other molecules involved in inflammatory response contribute to expanding brain damage.

The biological activity of tau depends on the degree of its phosphorylation. Hyperphosphorylation of tau depresses its activity to promote microtubule assembly and maintain their structure leading to instability of microtubules and impairment of axonal integrity and transport of molecules and organelles resulting in the collapse of cytoskeleton and reduction in neurotransmitter production and consequently neuronal death (Harrington, 2001).

Tau-l antibody recognizes tau only when it is dephosphorylated) Szendrei et al., 1993). In the present study, there was a significant downregulation of Tau-1 immunoreaction within the hippocampus of the orchiectomized rats indicating tau hyperphosphorylation. This could be attributed to the oxidative stress that may induce a kinase and phosphatase imbalance, leading to tau hyperphosphorylation.

The phosphorylation of tau is regulated by protein kinases and protein phosphatases (PP) including PP-2A, which is the most active enzyme in dephosphorylating the abnormally hyperphosphorylated tau (Liu et al., 2005). Jiang et al. (2007) clarified that inhibition of PP2A or activation of tau protein kinases could induce tau hyperphosphorylation.

In the present study, the orchiectomized rats treated either by testosterone or lemon peel extract showed ameliorating effects on the orchiectomy induced neurodegenerative changes.

Previous studies (Carla et al., 2012; Elnegris and Mohamed, 2012; Meydan et al., 2010)evaluated the ameliorating effect of testosterone supplementation in orchiectomized rats. Ahlbom et al. (2001) referred to the neuroprotective effect of testosterone to its antioxidant effect. Moreover, Papasozomenos and Shanavas (2002) clarified its role in the phosphorylation of tau protein.

Some studies have shown that the neuroprotective properties of androgens involve activation of a mitogen-activated protein kinase (MAPK) pathway) Nguyen et al., 2005; Gatson et al., 2006) which has been shown to increase neuronal survival) Cavanaugh, 2006; Hetman and Gozdz, 2004).

Natural products often provide more safety and fewer side effects than synthetic medications (Nofal et al., 2019). In the present study, for the first time up to the best of our knowledge, the ameliorating role of lemon peel extract on orchiectomy induced hippocampal neurodegeneration was investigated. It showed a marvelous neuroprotective effect via the significant downregulation of iNOS, Bax, GFAP and significant upregulation of Tau-1 indicating its antioxidant and antiapoptotic properties in addition to its beneficial role to control the gliosis and suppress Tau hyperphosphorylation. This may be attributed to its antioxidant effect in addition to its ability to raise the serum level of testosterone hormone as confirmed in our research.

Previous studies) Mohamed et al., 2014; Abdel Moneim, 2014; Okuyama et al., 2015) revealed neuroprotective effects of citrus peel compounds in the different experimental models, including hyperglycemic mice.

Hong et al. (2008) postulated that citrus peel extract could produce a slight increase in serum testosterone level as it is rich in vitamin $\mathrm{C}$, which reduces stress hormones such as cortisol. Not only that, but it also contains vitamin A, which is required for testosterone generation and can help lower estrogen level; thus, testosterone becomes more effective.

Also, citrus contains antioxidative compounds such as flavonoids (Green et al., 2011), which act by neutralizing the oxidizing free radicals (Abdel Moneim, 2014). Moreover, Okuyama et al. (2016) stated that auraptene (AUR), citrus peel component, exerted suppressive effects on astrocyte activation and neuronal cell death in the brain of a lipopolysaccharide -injected inflammation model. Furthermore, Okuyama et al. (2018) found that AUR and naringin (NGI) significantly suppressed tau phosphorylation in the hippocampus of hyperglycemic rats, and they referred this to its antioxidant properties.

\section{CONCLUSION}

The results of this study confirm the neurodegenerative effects of orchiectomy on the rat hippocampus, add new information to the known neuroprotective effects of testosterone, and provide a new insight into the possible use of lemon peel extract to enhance the neuroprotective effects after orchiectomy.

Funds:

No funding resources

Conflict of Interests:

No conflict of interests 
Citation: Lubna Taher Mahmoud Eid, et al., Comparative Study Between Lemon Peel Extract and Testosterone Supplementation on the Hippocampus of Orchiectomized Rat. Australian Journal of Basic and Applied Sciences, 13(6): 62-73. DOI: 10.22587/ajbas.2019.13.6.7

\section{Author contribution:}

all the authors contributed equally to this work.

\section{REFERENCES}

Abdel Moneim, A.E., 2014. Citrus peel extract attenuates acute cyanide poisoning-induced seizures and oxidative stress in rats. CNS NeurolDisord Drug Targets. 13(4): 638-646. doi:10.2174/1871527312666131206095142.

Acquaviva, R., Campisi, A., Murabito, P., Raciti, G., Avola, R., Mangiameli, S., Musumeci, I., Barcellona, M.L., Vanella, A., and Volti, G.L., 2004. Propofol attenuates peroxynitrite-mediated DNA damage and apoptosis in cultured astrocytes: An alternative protective mechanism. Anesthesiol,101(6): 1363-1371. doi: 10. 1097/00000542-200412000-00017.

Afolabi, A.O., Osho, O.O., and Alagbonsi, I.A., 2013. Tomato supplement ameliorates castration-induced oxidative stress in the rat. Afr J Biochem Res, 7(3): 33-38. doi: 10.5897/AJBR12.075.

Ahlbom, E., Prins, G.S., and Ceccatelli, S., 2001. Testosterone protects cerebellar granule cells from oxidative stress induced cell death through a receptor mediated mechanism. Brain Res,892(2): 255-262. doi.org/10.1016/S0006-8993(00)03155-3.

Bagetta, G., Piccirilli, S., Del Duca, C., Morrone, L.A., Rombola, L., Nappi, G., De Alba, J., Knowles, R.G., and Corasaniti, M.T., 2004. Inducible nitric oxide synthase is involved in the mechanisms of cocaine enhanced neuronal apoptosis induced by HIV-1 gp120 in the neocortex of rat. Neurosci.Lett, 356(3): 183-186. doi:10.1016/j.neulet.2003.11.065.

Bancroft, J., 2005. The endocrinology of sexual arousal. J Endocrinol, 186(3): 411-427. doi:10.1677/joe.1.06233.

Barreto, G., Veiga, S., Azcoitia, I., Garcia, S.L.M., and Garcia, O.D., 2007. Testosterone decreases reactive astroglia and reactive microglia after brain injury in male rats: role of its metabolites, estradiol and dihydrotestosterone. Eur J Neurosci, 25(10): 30393046. doi:10.1111/j.1460-9568.2007. 05563.x

Berman, D.M., Rodriguez, R., and Veltri, R.W., 2012. Development molecular biology and physiology of the prostate. CampbellWalsh Urology. 10th edn. In:Wein AJ, Kavoussi LR, Novick AC et al (eds), 12(04): 2533- $2569 .$.

Carla, B.M., Gallo, Alexandre, F., Miranda, Brunofelix- Patrico, Cristiane F., Ramos, Luiz, E.M, Cardosco, Waldemar, S., Costa, and Francisco, J.B., 2012. Effects of Castration and Hormone Replacement in the Urinary Bladder of Rats: Structural Ultrastructural, and Biochemical Analysis. Journal of Andrology, 33(4): 684-690. doi: 10.2164/jandrol.111.014159.

Cavanaugh, J.E., 2004. Role of extracellular signal kinase 5 in neuronal survival. Eur J Biochem, 271(11): 2056-2059. doi: 10.1111/j.1432-1033.2004. 04131.x.

Cencioni, C., Spallotta, F., Martelli, F., Valente, S., Mai, A., Zeiher, A.M., and Gaetano, C., 2013. Oxidative Stress and Epigenetic Regulation in Ageing and Age-Related Diseases. International Journal of Molecular Sciences. 14(9): 17643-17663. doi: 10.3390/ijms140917643.

Christoffersen, B., Raun, K., Svendsen, O., Fledelius, C., and Golozoubova, V., 2006. Evaluation of the castrated male SpragueDawley rat as a model of the metabolic syndrome and type 2 diabetes. Int J Obes (Lond), 30(8): 1288-1297. doi: 10.1038/sj.ijo.0803261

DeKosky, S.T., and Scheff, S.W., 1990. Synapse loss in frontal cortex biopsies in Alzheimer's disease: correlation with cognitive severity. Annals of Neurology, 27(5): 457- 464. doi: 10.1002/ana.410270502.

Demir, A., Tanidir, Y., Karadag, M.A., Atasoy, B.M., Bozkurt, S., Cecen, K., and Türkeri, L., 2015. Effects of testosterone treatment on recovery of rat spermatogenesis after irradiation. JPMA, 65(3): 300-305.

El-Mehi, A.E., and El-Sherif, N.M., 2014. Protective Effect of Defatted flaxseed on Urinary Bladder of Ovariectomized Albino Rats. Australian Journal of Basic and Applied Sciences, 8(18): 686-698.

Elnegris, H.M., and Mohamed, D., 2012. Effect of experimental orchiectomy on hippocampus of adult albino rat and the role of testosterone supplementation: a histological and immunohistochemical study. The Egyptian Journal of Histology, 35(2): 315325. doi: 10.1097/01.EHX.0000414775.48671.88.

Feldman, H.A., Longcope, C., Derby, C.A., Johannes, C.B., Araujo, A.B., and Coviello, A.D., 2002. Age trends in the level of serum testosterone and other hormones in middle-aged men: longitudinal results from the Massachusetts male aging study. J Clin Endocrinol Metab, 87(2): 589-598. doi:10.1210/jcem.87.2.8201.

Garcia, S.L.M., and Melcangi, R.C., 2006. Steroids and glial cell function. Glia, 54(6): 485-498. doi: 10.1002/glia.20404.

Gatson, J.W., Kaur, P., and Sigh, M., 2006. Dihydrotestosterone differentially modulates the mitogen-activated protein kinase and the phophiositide 3-kinase/Akt pathways through the nuclear and novel membrane androgen receptor in C6 cells. Endocrinology, 147(4): 2028-2034. doi:10.1210/en.2005-1395.

Goedert, M., Jakes, R., Crowther, R. A., Sixt, J., Lubkeo, U., Vandermeerent, M., Cras, P., Trojanowsk, J.Q., and Lee, V.M., 1993. The abnormal phosphorylation of tau protein at Ser-202 in Alzheimer disease recapitulates phosphorylation during development (fetal tau/adult tau/paired helical fIlament/neuropathology). Neurobiology, 90(11): 5066-5070. doi: 10.1073/pnas.90.11.5066.

Green, C.O., Wheatley, A.O., McGrowder, D.A., Dilworth, L.L., and Asemota, H.N., 2011. Modulation of antioxidant enzymes activities and lipid peroxidation products in diet-induced hypercholesterolemic rats fed ortanique peel polymethoxylated flavones extract. J Appl Biomed, 10: 91-101. doi: 10.2478/v10136-011-0014-3.

Gregory, E., McCloskey, M., and Landau, B., 2014. Profound loss of general knowledge in retrograde amnesia: evidence from an amnesic artist. Frontiers in Human Neuroscience, 287(8): 1

Hammond, J., Le, Q., Goodyer, C., Gelfand, M., Trifiro, M., and LeBlanc, A., 2001. Testosterone-mediated neuroprotection through the androgen receptor in human primary neurons. J Neurochem, 77(5): 1319-1326. doi:10.3389/fnhum.2014.00287. 
Citation: Lubna Taher Mahmoud Eid, et al., Comparative Study Between Lemon Peel Extract and Testosterone Supplementation on the Hippocampus of Orchiectomized Rat. Australian Journal of Basic and Applied Sciences, 13(6): 62-73. DOI: 10.22587/ajbas.2019.13.6.7

Harrington, C.R., 2001. The aetiology of Alzheimer's disease: diverse routes into a common Tau PathwayI. Aluminium and Alzheimer's disease; The science that describes the link.In: Exley C, Editor. Amsterdam: Elsevier Science. Chapter 5, p. 97-132.

Hetman, M., and Gozdz, A., 2004. Role of extracellular signal regulated kinases 1 and 2 in neuronal survival. Eur J Biochem, 271(11): 2050-2055. doi:10.1111/j.1432-1033.2004. 04133.x.

Hong, M.Y., Seeram, N.P., and Heber, D., 2008. Pomegranate polyphenols down-regulate expression of androgen-synthesizing genes in human prostate cancer cells overexpressing the androgen receptor. J Nutr Biochem, 19(12): 848-855. doi: 10.1016/j.jnutbio.2007.11.006.

Jacobs, N.S., Allen, T.A., Nguyen, N., and Fortin, N.J., 2013. Critical role of the hippocampus in memory for elapsed time. J Neurosci, 33(34): 13888-13893. doi: 10.1523/JNEUROSCI.1733-13.2013.

Jayaprakash, G.K., and Patil, B.S., 2007. In vitro evaluation of the antioxidant activities in fruit extracts from citron and blood orange. Food Chem,101(1): 410-418. doi.org/10.1016/j.foodchem.2005.12.038.

Jiang, F.A.N.G., Rong, L.I.U., Qing, T.I.A.N., Xiao-ping, H.O.N.G., Shao-hui, W.A.N.G., Fu-yuan, C.A.O., Xi-ping, P.A.N., and Jian-zhi, W.A.N.G., 2007. Dehydroevodiamine attenuates calyculin A-induced tau hyperphosphorylation in rat brain slices. Acta Pharmacol Sin, 28 (11): 1717-1723. doi:10.1111/j.1745-7254.2007. 00655.x.

Johnson, S., 2001. Gradual micronutrient accumulation and depletion in Alzheimer's disease. Med. Hypotheses, 56(6): 595-597. doi: $10.1054 /$ mehy.2000.1301.

Khasnavis, S., Ghosh, A., and Roy, A., 2017. Castration induces Parkinson disease pathologies in young male mice via inducible nitric-oxide synthase. J. Biol. Chem, 288(29): 20843-20855. doi: 10.1074/jbc.M112.443556.

Klapcinska, B., Jagsz, S., Sadowska-Krepa, E., Gorski, J., Kempa, K., and Langfort, J., 2008. Effects of castration and testosterone replacement on the antioxidant defense system in rat left ventricle. J PhysiolSci, 58(3): 173-177. doi: $10.2170 /$ physiolsci.RP002208.

Kordan, Y., 2010. Hormone therapy in metastatic prostate cancer. Turk Urol Sem, 1: 195- 200. doi: 10.4081/oncol. 2013.e6.

Liu, F., Grundke-Iqbal, I., Iqbal, K., and Gong, C.X., 2005. Contributions of protein phosphatases PP1, PP2A, PP2B and PP5 to the regulation of tau phosphorylation. Eur J Neurosci, 22(8): 1942-50. doi:10.1111/j.1460-9568.2005. 04391.X.

Marriott, H.M., Ali, F., Read, R.C., Mitchell, T.J., Whyte, M.K., 2004. Dockrell, D.H., Nitric oxide levels regulate macrophage commitment to apoptosis or necrosis during pneumococcal infection. FASEB J, 18(10): 1126- 1139. doi:10.1096/fj.03-1450fje.

Meydan, S., Kus, I., Tas, U., Ogeturk, M., Sancakdar, E., Dabak, D.O., Zararsız, I., and Sarsilmaz, M., 2010. Effects of testosterone on orchiectomy-induced oxidative damage in the rat hippocampus. Journal of Chemical Neuroanatomy, 40(4): 281-285. doi:10.1016/j.jchemneu.2010.07.006.

Mohamed, N.A.E., Amany, A., Tohamy, A.A., Elgamal, B., and Abdel Moneim, A.E., 2014. Ameliorative effect of citrus peel extract on castration-induced oxidative stress in liver and kidney of rats. Journal of Applied Pharmaceutical Science, 4(7): 064-068. doi: 10.7324/JAPS.2014.40711.

Moore, S.M., and Urban, R.J., 2004. An overview of the endocrinology of skeletal muscle. Trends Endocrinol Metab, 15(3): 110-115. doi:10.1016/j.tem.2004.02.009.

Nguyen, T.V.V., Yao, M., and Pike, C.J., 2005. Androgens activate mitogen-activated protein kinase signaling: Role in neuroprotection. J Neurochem, 94(6): 1639-1651. doi: 10.1111/j.1471-4159.2005. 03318.x.

Nofal, E.A., El-Habeby, M.M., El-Kholy, W.B., El-Akabawy, G.F., and Faried, M.A., 2019. Protective role of broccoli extract on estradiol valerate-induced polycystic ovary syndrome in female rats. Europian Journal of Anatomy. 23 (2): $121-129$.

Ogawa, T., Dobrinski, I., and Brinster, R.L., 1999. Recipient preparation is critical for spermatogonial transplantation in the rat. Tissue \& Cell, 31(5): 461-472. doi:10.1054/tice.1999.0060.

Okuyama, S., Morita, M., Kaji, M., Amakura, Y., Yoshimura, M., Shimamoto, K., Ookido, Y., Nakajima, M., and Furukawa, Y., 2015. Auraptene Acts as an Anti-Inflammatory Agent in the Mouse Brain. Molecules, 20(11): 20230-20239. doi: $10.3390 /$ molecules201119691.

Okuyama, S., Nakashima, T., Nakamura, K., Shinoka, W., Kotani, M., Sawamoto, A., Nakajima, M., and Furukawa, Y., 2018. Inhibitory Effects of Auraptene and Naringin on Astroglial Activation, Tau Hyperphosphorylation, and Suppression of Neurogenesis in the Hippocampus of Streptozotocin-Induced Hyperglycemic Mice. Antioxidants, 7(8): 109. doi: 10.3390/antiox7080109.

Okuyama, S., Semba, T., Toyoda, N., Epifano, F., Genovese, S., Fiorito, S., Taddeo, V.A., Sawamoto, A., Nakajima, M., and Furukawa, Y., 2016. Auraptene and Other Prenyloxyphenylpropanoids Suppress Microglial Activation and Dopaminergic Neuronal Cell Death in a Lipopolysaccharide-Induced Model of Parkinson's Disease. Int. J. Mol. Sci, 17(10): $1700-1716$. doi: $10.3390 /$ ijms 17101716.

Ortuno, A.A.P., Baidez, M.C., Gomez, I., Arcas, A.G., Porras, J.A., and Del Rio., 2006. Citrus paradise and Citrus sinensis flavonoids: Their influence in the defense mechanism against Penicillium digitatum. Food Chem, 98(2): 351-358. doi.org/10.1016/j.foodchem.2005.06.017.

Osterberg, E.C., Bernie, A.M., and Ramasamy, R., 2014. Risks of testosterone replacement therapy in men. Indian J Urol, $30(1): 2-7$. doi: 10.4103/0970-1591.124197.

Ozcan, S., Huri, E., Doluoglu, O.M., Karakan, T., Ozer, E., Fidanci, V., Eroglu, M., and Hucumenoglu, S., 2015. The Effect of Testicular Cryoablation on Testosterone Level in Rats: An Experimental Model of Histopathological Orchiectomy. Urol J, 12(4): 2256-2260. doi: 10.1016/S1569-9056(14)61617-1. 
Papasozomenos, S.C., and Shanavas, A., 2002. Testosterone prevents the heat shock-induced overactivation of glycogen synthase kinase-3b but not cyclin-dependent kinase 5 and c-Jun NH2-terminal kinase and concomitantly abolishes hyperphosphorylation of s: Implications for Alzheimer's disease. Proc Natl Acad Sci USA, 99(3): 1140-1145. doi:10.1073/pnas.032646799.

Ramesh, G., MacLean, G.A., Mario, T., and Philipp, T.M., 2013. Cytokines and Chemokines at the Crossroads of Neuroinflammation, Neurodegeneration, and Neuropathic Pain. Mediators of Inflammation J, 1-21. doi:10.1155/2013/480739.

Reali, C., Scintu, F., Pillai, R., Donato, R., Michetti, F., and Sogos, V., 2005. S100b counteracts effects of the neurotoxicant trimethyltin on astrocytes and microglia. J. Neurosci. Res, 81(5): 677-686. doi: 10.1002/jnr.20584.

Rhoden, E.L., Halmenschlager, G., Motta, G.A., Fagundes, L.S., MedeirosJr, J.S., Meurer, R., and Rhoden, C.R., 2017. Testosterone replacement maintains smooth muscle content in the corpus cavernosum of orchiectomized rats. Asian Journal of Urology, 4(4): 223-229. doi: 10.1016/j.ajur.2017.02.001.

Rhodes, M.E., and Frye, C.A., 2004. Androgens in the hippocampus can alter and be altered by, ictal activity. Pharmacol Biochem Behav, 78(3): 483-493. doi: 10.1016/j.pbb.2004.04.020.

Ryu, S.J., Ryu, D.S., Kim, J.Y, Park, J.Y., Kim, K.H., Chin, D.K., Kim, K.S., Cho, Y.E., and Kuh, S.U., 2015. Bone Mineral Density Changes after Orchiectomy using a Scrotal Approach in Rats. Korean J Spine, $12(2)$ : 55-59. doi: $10.14245 / \mathrm{kjs} .2015 .12 .2 .55$.

Salcedo, I., Tweedie, D., and Li, Y., 2012. Neuroprotective and neurotrophic actions of glucagon-like peptide-1: an emerging opportunity to treat neurodegenerative and cerebrovascular disorders. British Journal of Pharmacology Br J Pharmacol. 166(5): 1586-1599. doi: 10.1111/j.1476-5381.2012.01971.x.

Shin, M.S., Chung, K.J., Ko, I.G., Kim, S.H., Jin, J.J., Kim, S.E., Lee, J.M., Ji, E.S., Kim, T.W., Cho, H.S., Kim, C.H., Cho, Y.S., Kim, C.J., and Kim, K,H., 2016. Effects of surgical and chemical castration on spatial learning ability in relation to cell proliferation and apoptosis in hippocampus. Int Urol Nephrol, 48(4): 517-527. doi:10.1007/s11255-015-1200-0.

Spires-Jones, T.L., Stoothoff, W.H., de Calignon, A., Jones, P.B., and Hyman, B.T., 2009. Tau pathophysiology in neurodegeneration: a tangled issue.Trends Neurosci, 32(3): 150-159. doi: 10.1016/j.tins.2008.11.007.

Stuermer, E.K., Sehmisch, S., Tezval, M., Tezval, H., Rack, T., and Boekhoff, J., 2009. Effect of testosterone, raloxifene and estrogen replacement on the microstructure and biomechanics of metaphyseal osteoporotic bones in orchiectomized male rats. World $\mathbf{J}$ Urol, 27: 547-555. doi: 10.1007/s00345-009-0373-5.

Szendrei, G.I., Lee, V.M.Y., and Otvos, L., 1993. Progress in Molecular and Subcellular biology: Guidance Cues in the Developing Brain. J. Neurosci. Res, 34: 243-249.

Tamatani, M., Ogawa, S., Niitsu, Y., and Tohyama, M., 1998. Involvement of Bcl-2 family and caspase-3-like protease in NOmediated neuronal apoptosis. J. Neurochem, 71(4): 1588-1596. doi:10.1016/S0168-0102(98)82036-1.

Traish, A.M., Saad, F., Feeley, R.J., and Guay, A.T., 2009. The dark side of testosterone deficiency. J Androl, 30(5): 477-494. doi: $\underline{10.2164 / j a n d r o l .108 .007245 .}$ 